\title{
Measuring Vulnerability of Urban Korean Women to Weight Management Problems
}

\author{
Padmanand Madhavan Nambiar'1, Wojciech J. Florkowski', Dong-Kyun Suh ${ }^{2}$ \\ ${ }^{1}$ University of Georgia, Griffin, Georgia, USA \\ ${ }^{2}$ Rural Development Administration, Republic of Korea \\ Email:wojciech@uga.edu
}

Received 22 August 2015; accepted 7 December 2015; published 10 December 2015

Copyright (C) 2015 by authors and Scientific Research Publishing Inc.

This work is licensed under the Creative Commons Attribution International License (CC BY). http://creativecommons.org/licenses/by/4.0/

(c) () Open Access

\begin{abstract}
The study examines factors associated with BMI among urban women responsible for food shopping and preparation in the Republic of Korea. The preliminary ANOVA analysis of the survey data collected from women residing in seven major urban centers is followed by the logistic estimation of the equation identifying individual characteristics and household features changing the probability of undesirable BMI. Low income, low education, location, preference for convenience, sweettasting foods, and home vegetable processing are linked to BMI $\geq 25$. Respondents reporting weekly fruits and vegetable expenditure considered normal or above normal are less likely to be overweight. Profiles of urban women (in a country where more than 80 percent of people live in urban areas) vulnerable to becoming overweight or obese are developed and probabilities of changing the BMI based on respondent characteristics are calculated. There is a need for multipronged efforts including public and private sectors to address the increasing weight management problems among urban women to address differences in socioeconomic, location, health, and food choice factors predicting change in BMI.
\end{abstract}

\section{Keywords}

Socioeconomic Factors, Socioeconomic Status, BMI, Income, Education

\section{Introduction}

More than a billion adults are overweight and 300 million of them are clinically obese worldwide [1]. The weight management problem is particularly prevalent in many European, Australasian, and North American countries. In Asia, weight problems tend to be associated with certain groups within a society and are linked to income level [2]. In the Republic of Korea (ROK), there is a considerable increase in the number of people who 
cannot maintain a healthy body weight. An increasing number of Koreans are adopting a western lifestyle that is reflected in eating more fats, oils, and foods of animal origin than in the traditional Korean diet [3], and in decreasing physical activity [4]. The 1998 National Health and Nutrition Survey [5] reported an increase in the share of both obese and overweight individuals. These obesity rates were $1.7 \%$ and $3.0 \%$ (BMI $\geq 30.0 \mathrm{Kg} / \mathrm{m}^{2}$ ) and the overweight rates were $24.3 \%$ and $23.5 \%$ (BMI $25.0-29.99 \mathrm{Kg} / \mathrm{m}^{2}$ ) among adult men and women (between the ages of 15 years and 79 years), respectively. In 2005, the percentage of people with a BMI value of $\geq$ 25 increased to 31.7\% [6]. Recently, the OECD [7] reported an average obesity rate of 3.5\% in South Korea with $3.3 \%$ and $3.7 \%$ among adult men and women, respectively. The rates of overweight men and women are reported by OECD [7] as $23.7 \%$ and $30.3 \%$, respectively.

Though the obesity rates in the ROK are low among the OECD member countries, the overweight rates are increasing at an alarming rate and pose a potential threat to the wellbeing of the population. In the ROK, various forms of cancer and cardiovascular diseases are already among the major fatal causes of death and many such diseases have been linked to the inability to maintain a healthy weight [8]. Apart from the health consequences, there may be serious social consequences as well as economic costs. A retrospective cohort study [9] concludes that expected health costs are higher for persons who are overweight.

This study examines the influence of socioeconomic, demographic, and attitudinal factors on the likelihood of being an overweight urban Korean woman as measured by BMI. The results identify factors that predispose urban females to overweight or obesity problems. Further, the ROK is highly urbanized with about $80 \%$ of the population residing in cities and a focus on the urban population is highly relevant. The current analysis illustrates the applicability of results by quantifying the contribution of specific characteristics to the risk of overweight among Korean urban females. The higher share of obesity or overweight among women than men in the [7] and the main role of women in food shopping and preparation in Korean households establish a persuasive argument to develop profiles of women who are prone to be overweight or obese.

\section{Methods}

Several factors define the socioeconomic status (SES) of an individual [10] [11]. Major components of the SES are income, education, and occupation, and these components are included within the framework of a social level of analysis. These factors may contribute to overweight and obesity by influencing or enabling certain behaviors that regulate energy intake, energy expenditure, and metabolism [10]. Other factors, such as age, can also mediate the relationship between SES factors and weight. Also, general attitudes toward health play a role in relationship [12] and are important in weight management.

\section{Data, Variable Selection, and Empirical Specification}

The study involves a survey of women residing in seven major cities in the ROK: Seoul, Busan, Daegu, Incheon, Kwangju, Daejeon, and Ulsan. Among these cities, Seoul, the capital, has approximately 50\% of the total urban population. A total of 1100 households were subject to the survey distributed across the seven cities based on the population strength in each of these cities. The responsibility of data collection was entrusted to a commercial market research company that ensured proper recruitment randomness and representativeness in the selection of households. The survey focused on food consumption, shopping and food preferences. The participants were selected in proportion to the number of residents in each city and from households reflecting the income distribution.

Information on household income, age, education and occupation of the respondent, presence of children, whether the respondent smokes or not, whether the household pickles cabbage (for the traditional condiment kimchi), and the level of expenditures on fresh fruits and vegetables were collected during the interview.

Questions also probed attitudes toward food of Korean origin, ease in cooking, and willingness to pay more for sweeter foods. Respondents self-reported height and weight during the interviews. The BMI was calculated by dividing the weight in kilograms by squared height in meters. The current study considers normal weight as BMI value between 18 and 24.99; it is $\geq 0$, if the weight is less than this ideal weight.

Attitudes toward health are captured through the use of variables constructed based on smoking behavior, expenditures on fresh fruits and vegetables, willingness to pay more for sweeter foods, preference for convenience foods, home food processing, and preference for foods of Korean origin.

The empirical equation takes the general form: 


$$
\begin{aligned}
\text { Overweight } & =b_{0}+b_{1} I+b_{2} \text { smoke }+\sum_{i} C_{i} S_{i}+\sum_{j} D_{j} R_{j}+\Sigma_{k} E_{k} A_{k}, \\
& i=1, \cdots, 4 ; j=1, \cdots, 6 ; k=1, \cdots, 5,
\end{aligned}
$$

where $S_{i}$ refers to the group of socioeconomic and demographic variables, $R_{j}$ indicates the location variables, and $A_{k}$ stands for the group of variables constructed based on attitudes.

The logistic regression is employed for the estimation of this model, since the response variable is binary and in the current study equals one if the respondent's BMI $\geq 25$ and is 0 otherwise. The parameter estimates are interpreted in terms of the odds ratios calculated using the estimated coefficients [13]. Earlier studies justify the final selection of variables including the SES of individuals. Education, income, and occupation are the important socio-economic factors that have been included in similar studies. BMI was included in a study [14] that tracked a sample of people over a 20-year period and it was found negatively associated with both education and income levels. Getting information about income from surveys is difficult, especially from self-employed people [15]. Providing categories for responses related to income questions obtains a more accurate picture. Therefore household income was recorded in seven categories (Income). The first category included those households with less than $\$ 1700$, the last category with more than $\$ 5499$, and the remaining five categories with income distributed in between these figures (Table 1). Female labor participation was found to have a positive association with obesity rate [16].

\begin{tabular}{|c|c|c|c|}
\hline Variable name & Description and units of measurement & Mean or share ${ }^{\mathrm{a}}$ & Std dev. \\
\hline \multicolumn{4}{|c|}{ Dependent variable } \\
\hline Bmi25 & $=1$ if $\mathrm{bmi} \geq 25$ and 0 otherwise & 0.0828 & 0.2758 \\
\hline \multicolumn{4}{|c|}{ Independent variables } \\
\hline Income $^{\mathrm{b}}$ & Seven categories of monthly household income in US dollars & 4.3934 & 1.4600 \\
\hline Educ & Respondent's education in years & 13.0390 & 2.1855 \\
\hline Homemaker & $=1$ if the respondent is a homemaker and 0 otherwise & 0.4227 & 0.4943 \\
\hline Age & Age of the respondent in years & 41.5920 & 8.2862 \\
\hline Child & $=1$ if the household has children, 0 otherwise & 0.6504 & 0.4771 \\
\hline Inchon $^{c}$ & $=1$ household located in Inchon, 0 otherwise & 0.1072 & 0.3095 \\
\hline Daejeon $^{c}$ & $=1$ household located in Daejeon, 0 otherwise & 0.0755 & 0.2644 \\
\hline Daegu $^{c}$ & $=1$ household located in Daegu, 0 otherwise & 0.0914 & 0.2883 \\
\hline Ulsan $^{c}$ & $=1$ household located in Ulsan, 0 otherwise & 0.0390 & 0.1937 \\
\hline Busan $^{c}$ & $=1$ household located in Busan, 0 otherwise & 0.1267 & 0.3328 \\
\hline Kwangjuc ${ }^{c}$ & $=1$ household located in Kwangju, 0 otherwise & 0.0828 & 0.2758 \\
\hline Smoke & $=1$ If the respondent smokes, 0 otherwise & 0.0280 & 0.1651 \\
\hline Cab & $=1$ if the household pickles cabbage, 0 otherwise & 0.8124 & 0.3906 \\
\hline Expv & $\begin{array}{l}\text { Weekly expenditure on fruits and vegetables ( } 1 \text { if it is less than normal, } 2 \\
\text { if normal and } 3 \text { if above normal) }\end{array}$ & 2.0402 & 0.5057 \\
\hline Korean food ${ }^{\mathrm{d}}$ & $\begin{array}{l}\text { Response to the question "how important it is for you to have food be of } \\
\text { Korean origin" }\end{array}$ & 2.8733 & 0.4203 \\
\hline Easecook $^{\mathrm{e}}$ & $\begin{array}{l}\text { Response to the question "do you agree with the statement that new } \\
\text { agricultural and food technologies should aim at easing cooking" }\end{array}$ & 2.4653 & 0.7557 \\
\hline Willsweet & $\begin{array}{l}=1 \text { if the respondent is willing to pay more for foods that taste sweeter, } 0 \\
\text { otherwise }\end{array}$ & 0.3143 & 0.4645 \\
\hline
\end{tabular}

\section{Table 1. Summary statistics of variables.}

${ }^{\mathrm{a}}$ Share in case of a binary variable. ${ }^{\mathrm{b}}$ Monthly income categories: $1 \leq \$ 1700 ; 2=\$ 1700$ to $\$ 2299 ; 3=\$ 2300$ to $\$ 2899 ; 4=\$ 2900$ to $\$ 3499 ; 5=\$ 3500$ to $\$ 4499 ; 6=\$ 4500$ to $\$ 5499 ; 7 \geq \$ 5499$. ' Seoul is the benchmark for measuring the effects of location. ${ }^{\mathrm{d}} 1=$ not important; $2=$ neutral; $3=$ important. ${ }^{\mathrm{e}} 1$ = disagree; 2 = neutral; 3 = agree. 
The demographic variables included in earlier studies are the age of a respondent and the presence of children in the household. Age is found to have a positive influence on the prevalence of obesity in the ROK [4]. Presence of children also has a positive influence on obesity as revealed in a study conducted in the U.S. [16]. According to another study [17], the probability of being an overweight or obese person is inversely related to the population density in a metropolitan area. The current study distinguishes among the seven urban centers, treating Seoul as the reference location. Seoul has a population density of 16,189 people per $\mathrm{km}^{2}$ and is the largest among all cities with Busan in second place with a population density of only 4447 people per $\mathrm{km}^{2}$ [18].

Attitudes appear important in maintaining body weight. The aspects considered in the current study include five binary variables: health-oriented behavior, attachment to tradition and thrift, likeness towards fresh produce and preference for convenience and sweeter foods. "Smoke" represents a health behavior variable (Table 1) and was included in some of the previous studies including one conducted in the ROK [4] [19]. Negative correlation between smoking and BMI is reported in some studies [20] [21]. However, another study [22] concludes that this negative relationship may have resulted from endogeneity between smoking and body weight. Therefore, we are empirically testing this relationship in this study.

In Korean society, foods are not only perceived as providing nourishment, but also as possessing non-tangible attributes benefiting a consumer [23]. Therefore, the variable Koreanfood was included together with another variable, $\mathrm{Cab}$, accounting for a very specific traditional food that captures the effect of home pickling of cabbage. Cabbage is the main ingredient in kimchi, a Korean condiment, which is a major source of fiber and is consumed daily in significant volumes. The dietary fiber intake is helpful in weight management [24].

Vegetables have been a mainstay of the traditional diet and fruit consumption has dramatically increased in the ROK [5]. There is also epidemiological evidence that a high level of fresh produce consumption is associated with proper body weight. Therefore, the effect of the level of the weekly expenditure on fresh vegetables is captured through the inclusion of the variable Expv.

The variables Easecook and Willsweet refer to preferences (Table 1). Urban lifestyles and the increasing participation of women in the labor force stimulate the demand for convenience. Food distributors and food services respond by providing partially or fully cooked meals and individual dishes, but such dishes may contain ingredients that are high in calories. Consequently, frequent consumption of prepared dishes may supply more energy than a person needs in an urban setting (in contrast to a rural environment) and contribute to weight gain. The binary variable Willsweet assumes the value of 1 when a respondent expressed preference for sweet tasting foods. As a result of income growth, Korean consumers may choose to indulge this preference.

Three variables have three responses each. The variable Expv has a response of 1 if the expenditures of fresh fruits and vegetables were less than normal, response of 2 if the expenditures were normal, and response of 3 if expenditures were above normal. Another variable, Koreanfood, is a construct based on the responses to the question, "How important is it to you to have food of Korean origin?” Response 1 means it was important, 2 means neutral, and 3 means not important. Finally the variable Easecook is based on the question, "Do you agree with the statement that new agricultural and food technologies should aim at easing cooking?” Response 1 indicatesrespondent agreed with the statement, 2 is a neutral response, and 3 indicates disagreement with the statement. The binary response variable Bmi 25 takes a value of 1 if the BMI equals or is more than 25 and takes a value of 0 if the BMI is less than 25. A BMI of 25 or above indicates overweight or obesity. Table 1 shows descriptive statistics.

The empirical equation takes the following form:

$\mathrm{Y}=b_{0}+b_{1}$ Income $+b_{2}$ Educ $+b_{3}$ Homemaker $+b_{4}$ Age $+b_{5}$ Child $+b_{6}$ Inchon $+b_{7}$ Daejeon $+b_{8}$ Daegu $+b_{9}$ Ulsan $+b_{10}$ Busan $+b_{11}$ Kwangju $+b_{12}$ Smoke $+b_{13}$ Cab $+b_{14}$ Expv $+b_{15}$ Koreanfood $+b_{16}$ Easecook $+b_{17}$ Willsweet.

The above relationship, estimated using the logit technique, becomes a linear relationship between the log of odds and the explanatory variables. The log of odds is

$\ln \left(\frac{\pi}{1-\pi}\right)$, where $\pi$ is the probability of $Y=1$ (being overweight or obese) and $1-\pi$ is the probability of $Y=0$, respectively [13]. The antilog of an estimate $\left(\mathrm{e}^{\hat{b}_{i}}\right)$ is the odds ratio and its value greater than 1 implies that the event (the likelihood of being overweight) is more likely to happen in response to an increase in the explanatory variable; the odds ratio of less than 1 implies that the event is less likely to occur. Marginal effect of a continuous independent variable is the change in the probability of the occurrence of the event when that variable increases by one unit and that of a binary variable is the change in the probability when that variable changes its value from 0 to 1 . 


\section{Results}

Descriptive statistics of the sample are shown in Table 1. More than eight percent of the respondents have BMI greater than 25. An average respondent is 42 years old and 13 years of education. About $42 \%$ of the respondents are homemakers. Average monthly household is between the fourth category, $\$ 2900$ - \$3499, and fifth category, $\$ 3500$ - \$4499. Almost 50\% of respondents are from households located in the capital city, Seoul. The average weekly expenditures on fruits and vegetables are about normal.

A preliminary analysis of data using one way ANOVA (Table 2) identifies differences in means of characteristics of women between two subgroups. A total number of 821 women provided information to calculate their BMI and the subgroup with BMI $\leq 25$ has 753 observations; the second subgroup with BMI $>25$ has 68 observations. The results show that the significantly different means / proportions (at $5 \%$ significance level) between these two subgroups involve the following variables: household income, education and age, presence of children, location Kwangju, home preparation of pickle cabbage, attitude toward ease of cooking and willingness to pay more for sweeter foods.

\section{Logistic Regression Results}

The logistic regression employs the maximum likelihood method to estimate the equation. The likelihood ratio test for the global null hypothesis is significant at $<0.0001$ probability level indicating the overall explanatory power of the empirical model (Table 3). The goodness-of-fit of the model is examined by the Hosmer and Lemeshow Test (Table A1). The null hypothesis that the model fits the data is not rejected at 5\% significance level.

Table 3 shows the estimates, chi-square value, marginal effects, and odd ratios for the explanatory variables. Household income, education of the respondent, and the level of expenditures on fresh fruits and vegetables have a decreasing effect on the probability of being an overweight or obese woman, while residence in Kwangju, pickling cabbage at home and preference for convenience and sweet-tasting foods have the opposite effect.

Results show that an increase in the household income decreases the likelihood of having a higher BMI (by 1\% with a shift from lower to higher income category) suggesting that weight management is less of a problem if a respondent is from a high-income household. Additionally, one year of formal education above the average of 13 years lowers the probability of being in the overweight category by 1\%. Respondents who reported that the expenditure on fresh vegetables during the week preceding the survey was about normal or more than normal are less likely to be overweight (by $2 \%$ ) than those who believe that the expenditure was less than normal. Women

Table 2. ANOVA results for statistically significant differences in means of variables from groups with two BMI levels.

\begin{tabular}{ccccc}
\hline Variable Name & \multicolumn{2}{c}{ BMI $>25$} & \multicolumn{2}{c}{ BMI $\leq 25$} \\
\hline Mean & Std. dev. & Mean & Std. dev. \\
\hline Income*** & 3.6471 & 1.3904 & 4.4608 & 1.4482 \\
Education*** & 11.4265 & 2.5819 & 13.1846 & 2.0876 \\
Age in years*** & 45.9853 & 8.7750 & 41.1952 & 8.1306 \\
Child*** & 0.47059 & 0.5028 & $0.6666^{\mathrm{p}}$ & 0.4717 \\
Kwangju*** & $0.2500^{\mathrm{p}}$ & 0.4362 & $0.0677^{\mathrm{p}}$ & 0.2514 \\
Cabbage** & $0.9261^{\mathrm{p}}$ & 0.2629 & $0.8021^{\mathrm{p}}$ & 0.3987 \\
Easecook** & 2.6471 & 0.6410 & 2.4489 & 0.7634 \\
Willsweet*** & $0.5147^{\mathrm{p}}$ & 0.5035 & $0.2961^{\mathrm{p}}$ & 0.4569 \\
No: of observations & & & & 753 \\
\hline
\end{tabular}

Note: list includes only statistically significant variables. Asterisks indicate levels of statistical significance: $* *$ and $* * *$ denote signi-

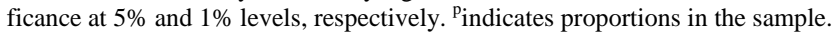


Table 3. Logit estimation results of the equation indicating the BMI greater than 25 using survey data from women in seven urban centers in the Republic of Korea.

\begin{tabular}{|c|c|c|c|c|c|c|}
\hline Variable name & Parameter estimate & Wald Chi-square & Marginal effect & Odds ratio & \multicolumn{2}{|c|}{ 95\% confidence interval (odds ratio) } \\
\hline Intercept & 0.2828 & 0.0218 & --- & --- & --- & --- \\
\hline Income & $-0.2241 * *$ & 4.0665 & -0.0102 & 0.7992 & 0.6428 & 0.9937 \\
\hline Educ & $-0.2642^{* * *}$ & 12.2655 & -0.0121 & 0.7678 & 0.6622 & 0.8901 \\
\hline Homemaker & -0.2026 & 0.4856 & $-0.0091^{\#}$ & 0.8166 & 0.4619 & 1.4437 \\
\hline Age & 0.0250 & 1.5354 & 0.0012 & 1.0253 & 0.9855 & 1.0668 \\
\hline Child & -0.3033 & 0.8544 & $-0.0144^{\#}$ & 0.7384 & 0.3881 & 1.4047 \\
\hline Inchon & -0.0695 & 0.0141 & $-0.0031^{\#}$ & 0.9329 & 0.2965 & 2.9350 \\
\hline Daejeon & 0.1597 & 0.0698 & $0.0077^{\#}$ & 1.1731 & 0.3587 & 3.8362 \\
\hline Daegu & 0.0123 & 0.0005 & $0.0006^{\#}$ & 1.0123 & 0.3579 & 2.8632 \\
\hline Ulsan & -0.2624 & 0.0618 & $-0.0107^{\#}$ & 0.7692 & 0.0971 & 6.0914 \\
\hline Busan & 0.5174 & 1.4243 & $0.0282^{\#}$ & 1.6777 & 0.7172 & 3.9245 \\
\hline Kwangju & $1.6314^{* * *}$ & 15.2111 & $0.1412^{\#}$ & 5.1110 & 2.2514 & 11.6026 \\
\hline Smoke & 0.0496 & 0.0039 & $0.0023^{\#}$ & 1.0509 & 0.2206 & 5.0055 \\
\hline Cab & $0.9071^{*}$ & 3.2782 & $0.0328^{\#}$ & 2.4779 & 0.9280 & 6.6160 \\
\hline Expv & $-0.4559 *$ & 3.0309 & -0.0208 & 0.6339 & 0.3794 & 1.0590 \\
\hline Koreanfood & -0.2920 & 0.8461 & -0.0133 & 0.7467 & 0.4008 & 1.3913 \\
\hline Easecook & $0.4238 *$ & 3.6768 & 0.0193 & 1.5278 & 0.9907 & 2.3562 \\
\hline Willsweet & $0.5996 * *$ & 4.1948 & $0.0305^{\#}$ & 1.8214 & 1.0262 & 3.2331 \\
\hline $\begin{array}{l}\text { Likelihood Ratio } \\
\text { Chi-square }\end{array}$ & 91.8219 & p-value & $<0.0001$ & & & \\
\hline
\end{tabular}

Pseudo $\mathrm{R}^{2}=0.196$. Asterisks indicate levels of statistical significance: *, ** and *** denote significance at $10 \%, 5 \%$, and $1 \%$ levels, respectively; ${ }^{\#} \mathrm{dy} / \mathrm{dx}$ is for discrete change of binary variable from 0 to 1 . The Likelihood Ratio Chi-square is 91.8219 with a p-value $<0.0001$.

that favored traditional Korean foods are 1.3\% to have lower probability of being overweight.

Women from households located in Kwangju are more likely (by 14\%) to become overweight than respondents residing in Seoul. The effect of residing in Kwangju on the probability of facing a weight management problem is substantial and offsets the effects of lowering the probability of being overweight associated with education or income. Females from households reporting processing cabbage are more likely (by 3.3\%) to fall in the category of having weight management problems than respondents who do not pickle cabbage at home. Women who agreed with the statement that new technologies should contribute to the ease of cooking are more likely (by $1.8 \%$ ) to have a higher BMI $(\geq 25)$ than those who disagree or who have no opinion about that statement. Women willing to pay more for foods that taste sweeter are also more likely to have a BMI exceeding 25 (by 3.1\%) than those who are not willing to pay a premium for such foods.

\section{Discussion}

Overall, results show that urban Korean women at risk of having weight management problems share characteristics of similar groups from other countries on different continents with a similar level of economic development. Also, factors that reduce the risk of being overweight or obese are alike. The similar profile of women at risk of having a high BMI suggests that despite different cultures, traditions, and history of economic development, the factors contributing to weight gain are the same and affect kindred population groups.

The key factors associated with unhealthy weight gain are household income level and education of an individual. The income effect is consistent with the results reported in previous studies [14] [25] [26]. Low-income households, given their small budgets, may have to contend with foods that contain relatively less expensive, but 
energy-dense ingredients. Refined grains, added sugars and added fats are among the lowest-cost sources of dietary energy [27]. Foods rich in such ingredients have become a part of the "westernized" diet in the ROK, and their consumption may lead to unhealthy body weight gain. The evidence from the current study that links a normal BMI to a high educational attainment supports earlier findings [16] [28] that less educated individuals have a higher probability of becoming overweight than more educated individuals.

An important outcome of this study is the negative relationship between the BMI and fresh fruit and vegetable expenditures. Several dietetic studies reported that a high consumption of fresh vegetables results in improved body weight management [29] [30]. The current study suggests that if a respondent perceives that their spending on fresh vegetables is above normal, then the probability of that person being in the overweight category decreases by $2.1 \%$ compared to the person who perceives that their expenditure was normal.

The results also indicate that the location of a household matters. The results obtained for Kwangju coincide with a study [31] which links low density and poor connectivity in street networks with a decrease in calorie expenditure leading to the increased incidences of overweight and obesity. The effect of residing in Kwangju on the probability of facing a weight management problem is substantial and suggests a need for location-specific efforts in preventing and lowering the incidence of unhealthy body weight.

Table 4 shows five hypothetical profiles of women across the seven cities, with different probabilities for becoming overweight. For example, according to the created profile the probability for working women who reside in Kwangju to be overweight is 0.1588 if they have an education of 13 years, whereas it increases to 0.2943 if there is only 10 years of education. Income and education tend to be inversely related, complicating a strategy aimed at inhibiting weight gain measured by the BMI. Public education programs are recommended, but unlikely to evenly influence behavior of low income, low education urban women.

The identification of a specific location facilitates efforts of informing and educating the population about weight management and the benefits of maintaining a healthy body weight. For example, the English government was trying to improve the infrastructure of some cities to increase physical activity like walking and cycling [32]. An agency in charge of public education may concentrate its efforts in a specific region, but it is warranted to further investigate regional differences in inclination to gain extra weight. Although a single area may experience a more severe weight problem, other regions are not likely to be immune and will also require a sustained preventive effort regarding weight management.

An indirect way to prevent urban Korean women from gaining weight may require the cooperation of public and private sectors. The promotion of eating fresh fruit and vegetables seems to have a strong positive effect on maintaining the proper weight. The Korean farm sector could participate in joint efforts with other private and public sector players in preventing obesity from becoming a chronic health problem.

The urban consumer demand for convenience has been confirmed in the current study. The ease of cooking is a proxy for the preference for convenience foods and a high consumption of convenience foods could contribute to unwanted body weight gain [33] [34]. The specific solutions must account for location and culture, because

Table 4. Probabilities of being overweight under assumed hypothetical characteristics of an urban Korean woman.

\begin{tabular}{cccccc}
\hline Location & Homemaker & Working woman & $\begin{array}{c}\text { Probability of being overweight } \\
\text { Working and } \\
\text { education of } 10 \text { years }\end{array}$ & $\begin{array}{c}\text { Working women with an } \\
\text { education of } 10 \text { years and } \\
\text { with children in households }\end{array}$ & $\begin{array}{c}\text { Working women who don't smoke, } \\
\text { have an education of } 10 \text { years and } \\
\text { with children in households }\end{array}$ \\
\hline Incheon & 0.0274 & 0.0333 & 0.0707 & 0.0532 & 0.0508 \\
Daejeon & 0.0342 & 0.0415 & 0.0873 & 0.0660 & 0.0630 \\
Daegu & 0.0296 & 0.0360 & 0.0763 & 0.0575 & 0.0548 \\
Ulsan & 0.0227 & 0.0276 & 0.0590 & 0.0443 & 0.0422 \\
Busan & 0.0482 & 0.0583 & 0.1204 & 0.0926 & 0.0877 \\
Kwangju & 0.1335 & 0.1588 & 0.2943 & 0.2354 & 0.2266 \\
\hline Seoul & 0.0293 & 0.0356 & 0.0754 & 0.0568 & 0.0542 \\
\hline
\end{tabular}

Hypothetical respondent and household characteristics: Household income = $\$ 2900$ to $\$ 3499$; education = 13 years; age = 42 years; households do not have children; respondents smoke; households prepare pickle cabbage; expenditure on fresh vegetables is normal; respondents consider it important to have foods of Korean origin; are neutral about the aim of new technologies to ease cooking; are willing to pay more for sweet foods. 
the exact meaning of convenience may vary. For example, the perception of what constitutes a reasonable amount of time to prepare and serve a meal may differ from city to city, but it influences food choices. Given the character of a Korean main meal, which often includes numerous side dishes and condiments, shaping expectations of convenience using knowledge of local dietary patterns and traditions will help to accomplish the goal of preventing excess weight gain.

The preference for sweet-tasting foods is natural. If the importance of preference for sweetness as a contributor to weight gain is to be reduced, product formulations controlled by food manufacturers may require changes. The changes could increase production costs and negatively influence revenues requiring consideration of possible regulations.

The formulated profiles of overweight women emphasize parental responsibility. Children with at least one obese parent are more likely to become obese than those children without obese parents [35]. Therefore, targeting households with children at the pre-school and elementary school level can be an effective strategy for preventing the incidence of overweight and obesity. Prevention of overweight and obesity problems is considered more cost effective than treatment of these problems [36].

The BMI is only one measure of a person's well-being. It is of broad interest because body weight is linked to the amount and type of consumed food. The association between unhealthy weight and disease incidence has been established and one way of preventing weight gain is to change food choices and quantity of consumed food. A change in food choices implies a shift in demand away from specific foods and food in general. A decrease in food demand negatively influences food sector revenues and leads to a conflict between that sector and efforts aiming at preventing consumers from gaining weight. However, to prevent obesity in the ROK from reaching the level witnessed in many post-industrial economies the efforts must be multipronged, coordinated, and sustained. For example, one study [37] found that the protein-rich oriental diet brings about body weight loss in a community-based weight control program.

\section{Conclusions}

Results of this study, in general, agree with those from earlier reports conducted in other countries. Therefore, it is worthwhile to consider sustained, coordinated; international efforts in combating the overweight and obesity problem. Agricultural subsidies, price policies, regulatory actions, and public health education implemented in a coordinated fashion may be necessary to achieve these goals. Although several initiatives have been undertaken in that area through the coordination of the International Obesity Task Force and WHO, the international coordination across scientific disciplines or sectors of the economy is very limited. An accelerated effort in preventing and reducing the excess weight problem seems necessary because overweight and obesity have become chronic public health issues threatening the welfare of global society.

There are some potential limitations in this study. The data included only female respondents and a generalization of results to the whole population requires careful consideration. Another issue is that BMI was calculated based on the self-reported height and weight, and the actual BMI may differ. According to a study [38] conducted among school students in the ROK, the self-reported height was higher and weight was lower than the actual values. Another study [39] concluded that, on average, older people over-reported their heights and older women under-reported their weights.

\section{Disclaimer}

The views expressed in this article are no necessarily the views of Rural Administration Authority of the Republic of Korea.

\section{References}

[1] World Health Organization (2004) Obesity and Overweight. http://www.who.int/mediacentre/factsheets/fs311/en/

[2] Tan, A.K., Yen, S.T. and Feisul, M.I. (2012) Determinants of Body Weight in Malaysia: An Ethnic Comparison. International Journal of Public Health, 57, 279-288. http://dx.doi.org/10.1007/s00038-011-0238-8

[3] Son, S.M. (2003) Food Consumption Trends and Nutrition Transition in Korea. Malaysian Journal of Nutrition, 9, 7-17. 
[4] Park, H.S., Yun, Y.S., Park, J.Y., Kim, Y.S. and Choi, J.M. (2003) Obesity, Abdominal Obesity, and Clustering of Cardio-Vascular Risk Factors in South Korea. Asia Pacific Journal of Clinical Nutrition, 12, 411-418.

[5] Ministry of Health and Welfare (1999) Report on 1998 National Health and Nutrition Survey (Dietary Intake Survey). Seoul, South Korea.

[6] Korea Health Industry Development Institute/Ministry of Health and Welfare (2006) Reports on 2005 National Health and Nutrition Survey. Nutrition Survey I \& II. Seoul, South Korea.

[7] Organization for Economic Co-Operation and Development (2003) S. Korea’s Obesity Rate Lowest in OECD. http://www.koreatimes.co.kr/www/news/nation/2009/04/113_42993.html

[8] Chennell, C. and Ridley, L. (2009) South Korea Food Market Overview Department of Primary Industries, Farm Services Victoria, Melbourne, Australia. http://www.dpi.vic.gov.au/dpi/nrenti.nsf/LinkView/8B58A731F9A07B72CA257678001B29503EAE47A0DB5D4984 CA25727A00781A83

[9] Thompson, D., Brown, J.B., Nichols, G.A., Elmer, P.J. and Oster, G. (2001) Body Mass Index and Future Healthcare Costs: A Retrospective Cohort Study. Obesity Research, 9, 210-218. http://dx.doi.org/10.1038/oby.2001.23

[10] Sobal, J. (1991) Obesity and Socioeconomic Status: A Framework for Examining Relationships between Physical and Social Variables. Medical Anthropology, 13, 231-247. http://dx.doi.org/10.1080/01459740.1991.9966050

[11] Adler, N.E., Boyce, T, Chesney, M.A., Cohen, S., Folkman, S., Kahn, R.L. and Syme, S.L. (1994) Socioeconomic Status and Health: The Challenge of the Gradient. American Psychologist, 49, 15-24. http://dx.doi.org/10.1037/0003-066X.49.1.15

[12] Brown, A.F., Ettner, S.L., Piette, J., Weinberger, M., Gregg, E., Shapiro, M.F., Karter, A.J., Safford, M., Waitzfelder, B., Prata, P.A. and Beckles, G.L. (2004) Socioeconomic Position and Health among Persons with Diabetes Mellitus: A Conceptual Framework and Review of the Literature. Epidemiologic Reviews, 26, 63-77. http://dx.doi.org/10.1093/epirev/mxh002

[13] Mendenhall, W. and Sincich, T. (1996) A Second Course in Statistics: Regression Analysis. 6th Edition, Prentice Hall, Upper Saddle River.

[14] Flegal, K.M., Harlan, W.R. and Landis, J.R. (1988) Secular Trends in Body Mass Index and Skinfold Thickness with Socioeconomic Factors in Young Adult Women. American Journal of Clinical Nutrition, 48, 535-543.

[15] Åstebro, T. and Chen, J. (2014) The Entrepreneurial Earning Puzzle: Mismeasurement or Real? Journal of Business Venturing, 29, 88-105. http://dx.doi.org/10.1016/j.jbusvent.2013.04.003

[16] Nayga, R. (1999) Sociodemographic Factors Associated with Obesity in the USA. Journal of Consumer Studies and Home Economics, 23, 161-164. http://dx.doi.org/10.1046/j.1365-2737.1999.00095.x

[17] Lopez, R. (2004) Urban Sprawl and Risk for Being Overweight or Obese. American Journal of Public Health, 94, 1574-1579. http://dx.doi.org/10.2105/AJPH.94.9.1574

[18] (2015) South Korea: Cities. http://www.citypopulation.de/KoreaSouth-Mun.html

[19] Kim, H. and Ruger, J.P. (2010) Socioeconomic Disparities in Behavioral Risk Factors and Health Outcomes by Gender in the Republic of Korea. BMC Public Health, 10, 195-214. http://dx.doi.org/10.1186/1471-2458-10-195

[20] Loureiro, M.L. and Nayga, R.M. (2005) Obesity Rates in OECD Countries: An International Perspective. Paper Prepared for Presentation at the EAAE XI Congress, Copenhagen.

[21] Fang, H., Ali, M.M. and Rizzo, J.A. (2009) Does Smoking Affect Body Weight and Obesity in China? Economics and Human Biology, 7, 334-350. http://dx.doi.org/10.1016/j.ehb.2009.07.003

[22] Chen, Z., Yen, T.S. and Eastwood, B.D. (2007) Does Smoking Have a Casual Effect on Weight Reduction? Journal of Family and Economic Issues, 28, 49-67.

[23] Wahlqvist, L.M.K. and Wattanapenpaiboon, N. (2005) Functional Foods and Their Impact on Nutrition and Health: Opportunities in the Asia Pacific. In: Shi, J., Ho, C. and Shahidi, F., Eds., Asian Functional Foods, CRC Press. Boca Raton, FL, 1-20.

[24] Park, K. and Rhee, S. (2005) Functional Foods from Fermented Vegetable Products: Kimchi (Korean Fermented Vegetables) and Functionality. In: Shi J., Ho C., Shahidi F. Eds, Asian Functional Foods, CRC Press, Boca Raton, 341-380.

[25] Lantz, P.M., House, J.S., Lepkowski, J.M., Williams, D.R., Mero, R.P. and Chen, J. (1998) Socioeconomic Factors, Health Behaviors, and Mortality-Results from a Nationally Representative Prospective Study of US Adults. Journal of the American Medical Association, 279, 1703-1708. http://dx.doi.org/10.1001/jama.279.21.1703

[26] Yoo, S., Cho, H. and Khang, Y. (2010) General and Abdominal Obesity in South Korea, 1998-2007: Gender and Socioeconomic Differences. Preventive Medicine, 51, 460-465. http://dx.doi.org/10.1016/j.ypmed.2010.10.004 
[27] Drewnowski, A. and Darmon, N. (2005) The Economics of Obesity: Dietary Energy Density and Energy Cost. The American Journal of Clinical Nutrition, 82, 265S-73S.

[28] Vernay, M., Malon, A., Oleko, A., Salanave, B., Roudier, C., Szego, E., Deschamps, V., Hercberg, S. and Castetbon, K. (2009) Association of Socioeconomic Status with Overall Overweight and Central Obesity in Men and Women: the French Nutrition and Health Survey 2006. BMC Public Health, 9, 215-222. http://dx.doi.org/10.1186/1471-2458-9-215

[29] Bazzano, L.A., He, J., Ogden, L.G., Loria, C.M., Vupputuri, S., Myers, L. and Whelton, P.K. (2002) Fruit and Vegetable Intake and Risk of Cardiovascular Disease in US Adults: The First National Health and Nutrition Examination Survey Epidemiologic Follow-Up Study. American Journal of Clinical Nutrition, 76, 93-99.

[30] Tohill, B.C. (2005) Dietary Intake of Fruit and Vegetables and Management of Body Weight. Joint FAO/WHO Workshop on Fruit and Vegetables for Health, Kobe, 1-3 September 2004, 52 p.

[31] Plantinga, A.J. and Bernell, S. (2005) A Spatial Economic Analysis of Urban Land Use and Obesity. Journal of Regional Science, 45, 473-492. http://dx.doi.org/10.1111/j.0022-4146.2005.00380.x

[32] Musingarimi, P. (2009) Obesity in the UK: A Review and Comparative Analysis of Policies within the Devolved Administrations. Health Policy, 91, 10-16. http://dx.doi.org/10.1016/j.healthpol.2008.11.004

[33] French, S.A., Harnack, L. and Jeffery, R.W. (2000) Fast Food Restaurant Use among Women in the Pound of Prevention Study: Dietary, Behavioral, and Demographic Correlates. International Journal of Obesity, 24, 1353-1359. http://dx.doi.org/10.1038/sj.ijo.0801429

[34] Wang, M.C., Kim, S., Gonzalez, A.A., MacLeod, K.E. and Winkleby, M.A. (2007) Socioeconomic and Food-Related Physical Characteristics of the Neighbourhood Environment Are Associated with Body Mass Index. Journal of Epidemiology and Community Health, 61, 491-498. http://dx.doi.org/10.1136/jech.2006.051680

[35] Organization for Economic Co-operation and Development (2010) Obesity and the Economics of Prevention: Fit Not Fat-Korea Key Facts. http://www.oecd.org/korea/obesityandtheeconomicsofpreventionfitnotfat-koreakeyfacts.htm

[36] International Obesity Task Force Secretariat (2002) The Global Challenge of Obesity and the International Obesity Task Force. http://www.iuns.org/the-global-challenge-of-obesity-and-the-international-obesity-task-force/

[37] Joo, N.S., Park, Y.W., Park, K.H., Kim, C.W. and Kim, B.T. (2011) Application of Protein-Rich Oriental Diet in a Community-Based Obesity Control Program. Yonsei Medical Journal, 52, 249-256. http://dx.doi.org/10.3349/ymj.2011.52.2.249

[38] Bae, J., Joung, H., Kim, J.Y., Kwon, K.N., Kim, Y. and Park, S.W. (2010) Validity of Self-Reported Height, Weight, and Body Mass Index of the Korea Youth Risk Behavior Web-based Survey Questionnaire. Journal of Preventive Medicine \& Public Health, 43, 396-402. http://dx.doi.org/10.3961/jpmph.2010.43.5.396

[39] Ezzati, M., Martin, H., Skjold, S., Vander Hoorn, S. and Murray, C.J. (2006) Trends in National and State-Level Obesity in the USA after Correction for Self-Report Bias: Analysis of Health Surveys. Journal of the Royal Society of Medicine, 99, 250-257. http://dx.doi.org/10.1258/jrsm.99.5.250 


\section{Appendix}

Table A1. Results of Hosmer and Lemeshow Goodness-of-Fit Test.

\begin{tabular}{|c|c|c|c|c|c|}
\hline \multicolumn{6}{|c|}{ Partition for the Hosmer and Leme show Test } \\
\hline \multirow[t]{2}{*}{ Group } & \multirow[t]{2}{*}{ Total } & \multicolumn{2}{|c|}{ Bmi25 = 1} & \multicolumn{2}{|c|}{ Bmi25 = 0} \\
\hline & & Observed & Expected & Observed & Expected \\
\hline 1 & 82 & 1 & 0.56 & 81 & 81.44 \\
\hline 2 & 82 & 1 & 1.20 & 81 & 80.80 \\
\hline 3 & 82 & 3 & 1.82 & 79 & 80.18 \\
\hline 4 & 82 & 7 & 2.56 & 75 & 79.44 \\
\hline 5 & 83 & 3 & 3.41 & 80 & 79.59 \\
\hline 6 & 82 & 2 & 4.37 & 80 & 77.63 \\
\hline 7 & 82 & 4 & 5.66 & 78 & 76.34 \\
\hline 8 & 82 & 9 & 7.56 & 73 & 74.44 \\
\hline 9 & 82 & 7 & 11.62 & 75 & 70.38 \\
\hline 10 & 82 & 31 & 29.25 & 51 & 52.75 \\
\hline \multicolumn{2}{|c|}{ Chi-Square: 13.6834} & \multicolumn{2}{|c|}{ Degrees of freedom: 8} & \multicolumn{2}{|c|}{ Pr > ChiSq: 0.0904} \\
\hline
\end{tabular}

